\title{
Hamartoma-adenoma-carcinoma sequence in a solitary Peutz-Jeghers type sigmoid polyp
}

\author{
Altonbary $\mathrm{AY}^{1^{*}}$, Bahgat $\mathrm{MH}^{1}$ and Elkashef $\mathrm{WF}^{2}$ \\ ${ }^{1}$ Department of hepatology and gastroenterology, Mansoura specialized medical hospital, Mansoura, Egypt \\ ${ }^{2}$ Department of pathology, Mansoura faculty of medicine, Mansoura, Egypt
}

\section{Case report}

A 35-year-old male was referred to our hospital complaining for bleeding of per rectum. Colonoscopy from anus to the terminal ileum revealed only a solitary pedunculated polyp in the sigmoid colon and polypectomy was performed without complications (Figure 1). He had no mucocutaneous pigmentation or family history of Peutz-Jeghers syndrome (PJS). Histopathological examination revealed polypoid structure with hyperplastic epithelial covering. And, the underlying core showed branching smooth muscle fibers (Figure 2a). The presence of muscle fibers confirmed by Desmin and alpha smooth muscle actin (SMA) immunehistochemical staining (Figure 3). Epithelial covering showed moderate pleomorphism with moderate nuclear atypia and atypical mitotic figures (Figure 2b). The polyp was diagnosed as a hamartomatous polyp with dysplastic foci.

\section{Discussion}

A Peutz-Jeghers polyp without either mucocutaneous pigmentation

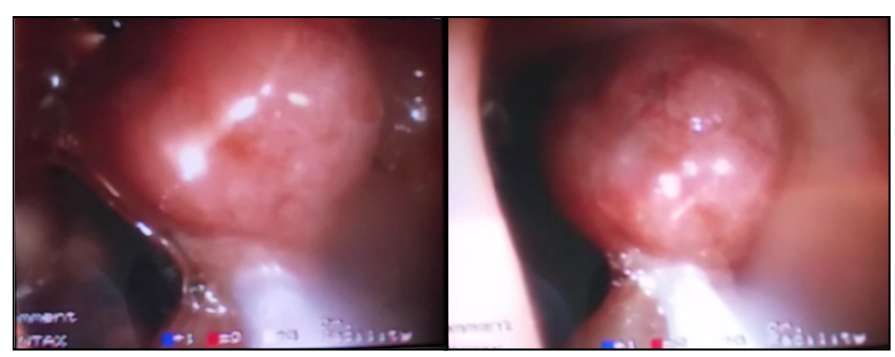

Figure 1: Solitary pedunculated polyp in the sigmoid colon during snare polypectomy.

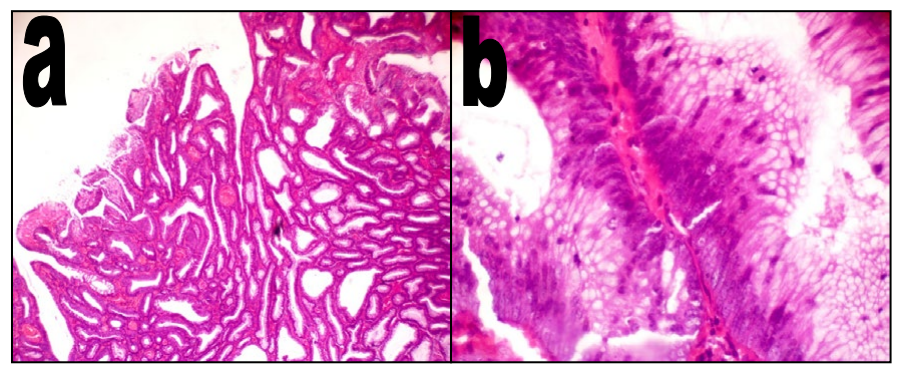

Figure 2: [a] Polypid mass with irregular hamartomatous glands (H\&E x40), [b] epithelial covering shows moderate dysplasia with little mitosis (H\&E x400).

Copyright: (C2016 Altonbary AY. This is an open-access article distributed under the terms of the Creative Commons Attribution License, which permits unrestricted use, distribution, and reproduction in any medium, provided the original author and source are credited.

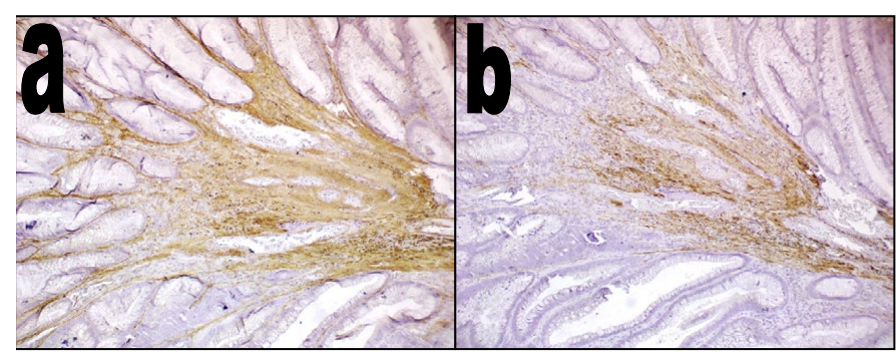

Figure 3: [a] Positive Desmin staining in smooth muscle fibers within the core (100x), [b] positive $\alpha$ SMA staining in smooth muscle fibers within the core $(100 \mathrm{x})$.

or a positive family history was described as a solitary Peutz-Jeghers (PJ) type hamartomatous polyp. which has been suggested to be a clinical entity different from PJS [1]. The malignant potential of solitary P-J type polyps is unclear; however, the hypothesis of hamartoma-adenomacarcinoma sequence has been suggested [2]. Only 28 previous case reports of solitary P-J type polyps were found. One polyp was located in the stomach, 21 in the small intestine, and 6 in the colon. Only 3 cases of malignant transformation in a solitary P-J-type polyp have been reported to date; one polyp was located in the duodenum, and the others were colorectal [3]. The present case is the $3^{\text {rd }}$ case report of malignant transformation in a colorectal P-J type polyp, supporting the hypothesis of hamartoma-adenoma-carcinoma sequence.

\section{Abbreviations}

PJS: Peutz-Jeghers syndrome; SMA: smooth muscle actin

\section{References}

1. Nebril BA, Filgueira LT, Calvo PA, García RG, Rodríguez GD, et al. (1993) Solitary hamartomatous duodenal polyp; a different entity: report of a case and review of the literature. Surgery Today 23: 1074-1077.

2. Bosman FT (1999) The hamartoma-adenoma-carcinoma-sequence. J Pathol 188: 9-13.

3. Arima S, Kunimura T, Matsuo K, Hobo T, Nogaki K, et al. (2010) Solitary PeutzJeghers type colorectal polyp with hamartoma-adenoma-carcinoma sequence in a nonPeutz-Jeghers syndrome patient. Showa Univ J Med Sci 22: 69-72.

Correspondence to: Dr. Ahmed Youssef Altonbary, Department of hepatology and gastroenterology, Mansoura specialized medical hospital, Mansoura, Egypt, Tel. +201005100091; E-mail: a.tonbary@gmail.com

Received: March 01, 2016; Accepted: April 20, 2016; Published: April 23, 2016 
Altonbary AY (2016) Hamartoma-adenoma-carcinoma sequence in a solitary Peutz-Jeghers type sigmoid polyp 